\title{
INFUENCE OF CONSTRUCTIVE PARAMETERS ON THE PERFORMANCE OF TWO INDIRECT EVAPORATIVE COOLER PROTOTYPES
}

Ana Tejero González, Manuel Andrés Chicote, Eloy Velasco Gómez,

Francisco J a vier Rey Martínez

This is a $n$ Accepted Manusc nipt of an article published by Esevier.

Applied Thermal Engineering, 2013, Volume 51, Issues 1-2, Pages 1017-1025, ISSN

1359-4311 https:// doi.org/10.1016/i.appltherma leng. 2012.10.054

(c) (1) $\Theta \Theta$ 


\section{Abstract}

Two equally-sized cross-flow heat exchanger prototypes have been designed with a total heat exchange area of $6 \mathrm{~m}^{2}$ and $3 \mathrm{~m}^{2}$ respectively, constructed with polycarbonate hollow panels of different cross-section. They are connected into a heat recovery cycle within the whole experimental setup constructed for the tests, which mainly consists of: an Air Handling Unit to simulate the outdoor a irstream conditions, a conditioned climate chamber, and a water circuit to provide the water supply required. They have been experimentally characterised in two operating modes in order to determine how evaporative cooling improves heat recovery in each case, focusing on the influence of modifying the constructive characteristics. To perform the evaporative cooling process, water is supplied to the exhaust airstream. Results are studied considening how constructive issues, outdoor air volume flow rate and temperature, as well as operating mode influence on the performance obtained. An Analysis of Variance shows how outdoor a ifflow has a key role in the performance of the systems; whereas entering outdoor air temperature determines cooling capacities. Improvements introduced by larger heat exchange areas compensate with their corresponding smaller cross sections, which hinder water-a ir distribution on the exhaust a ir side of the heat exchanger. Finally, these small devic es achieve cooling capacities of up to $800 \mathrm{~W}$, being able to partly support ventilation load and achieving around $50 \%$ of energy saving in ventilation cooling.

\section{Keywords}

Indirect Evaporative Cooling; Heat Recovery; Plastic Heat Exchanger, Heat Exchange Area; Cooling Capacity; Themal Conductance. 


\section{Introduction}

Our way of life nowadays requires an availability of energy that is however restricted by serious problems such as dependency on sources, nise in fossil fuel prices or the environmental awa reness on the impact involved. Consequently, actions are being driven to reduce energy consumption [1].

Partic ularly, the building sector appears to entail great potential of energy reduction, as it involves around $40 \%$ of the total European energy demand, mainly due to the high requirements of ventilation and themal comfort expected in conditioned spaces. It is also worth pointing out that space cooling in summer is gaining importance, with the consequent electric energy demand peaks. Taking into consideration that up to a $20 \%$ of the energy consumed in buildings could be saved, it seems obvious that the European Union focuses many of the new dispositions on energy saving in this field [2].

One of the main targets for energy saving is the recovering of residual energy of exhaust airstreams coming from conditioned spaces, due to the high ventilation rates established to achieve the expected Indoor Air Quality. Heat-recovery systems allow reducing the energy consumption of HVAC systems installed to meet the themal comfort required by preconditioning the a irstream supplied for ventilation [3, 4]. Air to air systems can be simply sensible heat exchangers, or permit total heat recovery. However, their implantation is restricted by the expensive investment involved and their considerable size $[5,6]$.

Exhaust airstream heat recovery can be improved by implementing an evaporative cooling process $[7,8,9]$. The great feature of this process is that it is a natural phenomenon which occurs when non-saturated air comes into contact with water, water eva porates into the a ir, reducing this way its dry-bulb temperature. Thus, it is a process of heat and mass transfer, based on the transformation of sensible heat into latent heat [10].

The ideal adiabatic saturation process determines the operation of most evaporative systems. In the theoretic al process, water is recirculated, mainta ining its temperature close to the adiabatic saturation temperature of inlet air, then the airstream dry bulb temperature decreases during the evaporative process, reaching the value of its saturation temperature when leaving the system. However, the adiabatic saturation temperature is merely the theoretical limit up to which air could be ideally cooled. Furthemore, the possibilities of evaporative cooling depend inversely on the relative air humidity [10]. Consequently, the application of this phenomenon in air-conditioning is an interesting altemative to reduce energy demand, provided that outdoor a ir relative humid ity falls within certa in limits, and so it is particularly interesting in dry climates [11]. In this line, Spain presents a wide range of different climates, among which performance of evaporative cooling devices would vary considerably [12]. However, performance of an indirect evaporative cooler operating with retum a ir into a heat recovery cycle will be independent of the entering outdoor a ir humidity [13]. Maheshwari et al [14] successfully developed an indirect evaporative cooler operating with airflows of $1180 \mathrm{l} / \mathrm{s}$ to achieve energy savings of 12418 and $6320 \mathrm{kWh}$ in interior and coastal areas in Kuwait. Moreover, application in the Mediterranean region of indirect 
evaporative cooling operating with retum air has been proved to reduce energy consumption mainta ining themal comfort requirements, as shows simulation results given by Jaber\& Ajib [15], in whose work $1100 \mathrm{l} / \mathrm{s}$ were treated covening over $60 \%$ of the cooling demand.

In this study, two heat exchanger prototypes for heat recovery pemitting their operation as indirect evaporative coolers are proposed. The evaporative cooling phenomenon is performed through one side of the heat exchanger, thus avoiding humidification of the airstream supplied to the conditioned space [16]. Both systems are made of the same material and have same global size, differing only on their total heat exchange area and airpaths width.

For the manufacturing, polycarbonate is considered regarding its low cost and weight, preventing comosion additionally. Due to the negligible effect of low themal conductivity in thin plates [17], plastic materials were firstly used for heat exchangers long ago [18] and are still being considered for their fea sibility [19]. Within this research line, Delfani et. al [20] proved a plastic indirect evaporative cooler to successfully pre-cool $0.472 \mathrm{~m} 3 / \mathrm{s}$ of supplied air, being able to reduce cooling loads up to $75 \%$ in temperate outdoor conditions. They also proved that acceptable operating outdoor conditions could be widened by combining it with a direct evaporative cooling unit [21]. Moreover, polycarbonate panels were already considered by Kragh et al. [22] for a successful heat-recovery during heating season, taking advantage of plastic material to face condensing problems.

In previous studies, a heat exchanger prototype made of narrow polycarbonate panels was constructed and characterised [8]. In present work, the ma in objective is constructing a new prototype with wide polycarbonate panels, only modifying the original constructive characteristic s to ma inta in the ma in a dvantages of simplic ity, cheapness and small size.

The a im presented here is thus to experimentally compare the two equally sized plastic heatexchanger systems, of different total heat exchange area and air-water paths, operating with retum air from a conditioned space. This allows determining how these two characteristics influence on their behaviour, throwing light on the performance of the evaporative cooling phenomenon inside the panels. Then it will be possible to determine which design would be of most interest.

\section{Experimental Facility and Methodology}

\subsection{Description of the two prototypes: manufacturing, installation and operation}

Two heat exchanger prototypes made of polycarbonate hollow panels arranged vertically and equally spaced are tested to study the possibilities of recovering the cooling potential of an exhaust airstream from a conditioned space, to pre-cool ventilation air in summer conditions. The systems differ from each other in the polycarbonate panels' width, namely 4 $\mathrm{mm}$ and $9 \mathrm{~mm}$ respectively (figure 1). Then, they will be called from now NP ("narrow" polycarbonate panels prototype) and WP ("wide" panels prototype). Figures $2 a$ and $2 b$ show 
a view of both prototypes under construction. The main geometric characteristics of both systems are gathered in table 1, and the most representative are shown in figure 3.

To experimentally characterise each system, they are installed in the laboratory within the whole experimental setup operating in a heat-recovery cycle (figure 4). This experimental fac ility ma inly consists of:

- An Air Handling Unit (AHU) that supplies the outdoor a irstream in summer conditions to be treated.

- A climate chamber where pre-cooled a ir from the prototype is supplied. Comfort conditions are ensured here thanks to an auxiliary heat pump.

- A water circuit consisting of a lower tank, a water pump, an upper water distributor and the required ducts.

- The a ir ducts connec ting these systems into a heat-rec overy cycle.

- The measurement equipment in the key points of the installation (at the prototype's inlets and outlets).

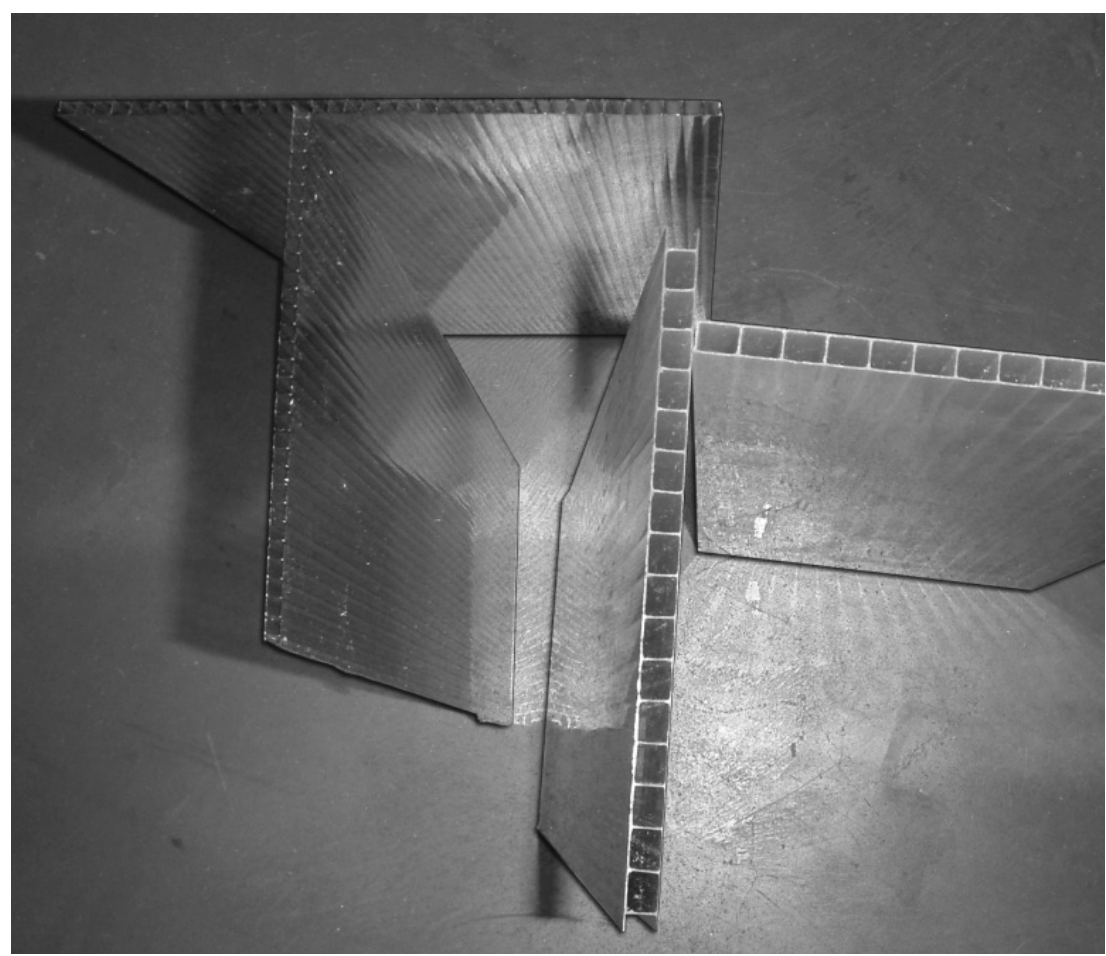

Fig. 1. Detail of the polycarbonate panels cross section 


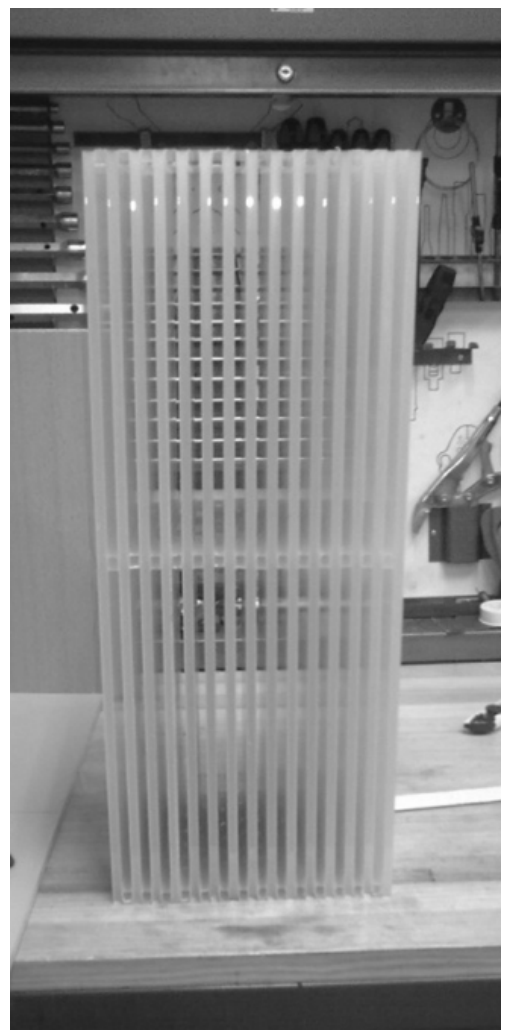

Fig. 2. a. View of prototype WP under construction

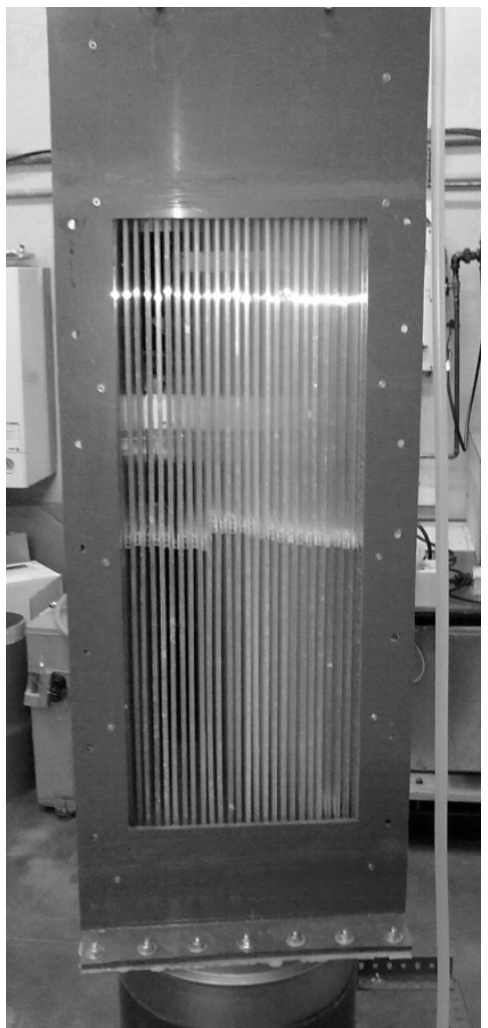

Fig. 2. b. View of prototype NP under construction, assembled

During the basic operating mode, the system behaves as a mere heat exchanger to precondition outdoor a ir that flows through the space between panels, recovening the residual energy of exhaust air retuming from a conditioned space, which flows upwards inside the hollow panels. In this case, heat transfer occurs from the outdoor airstream in summer conditions to the exhaust a irstream, which is in comfort conditions, through the system plastic walls. This operating mode is shown in figure 3. 


\section{Exhaust air}

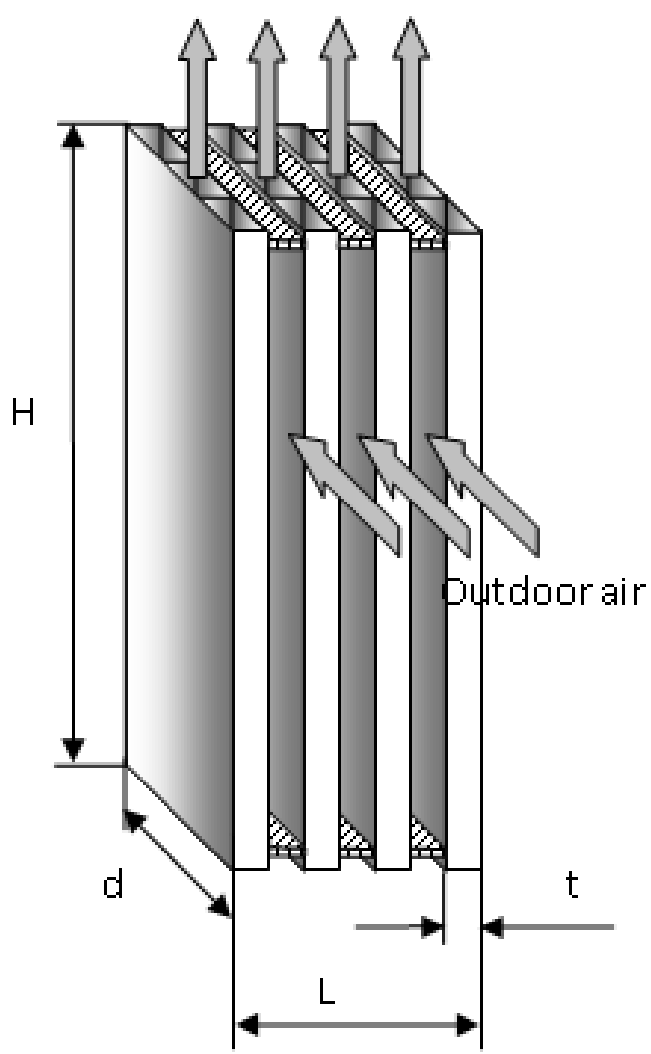

Fig. 3. Scheme of the systems' operation in the first mode.

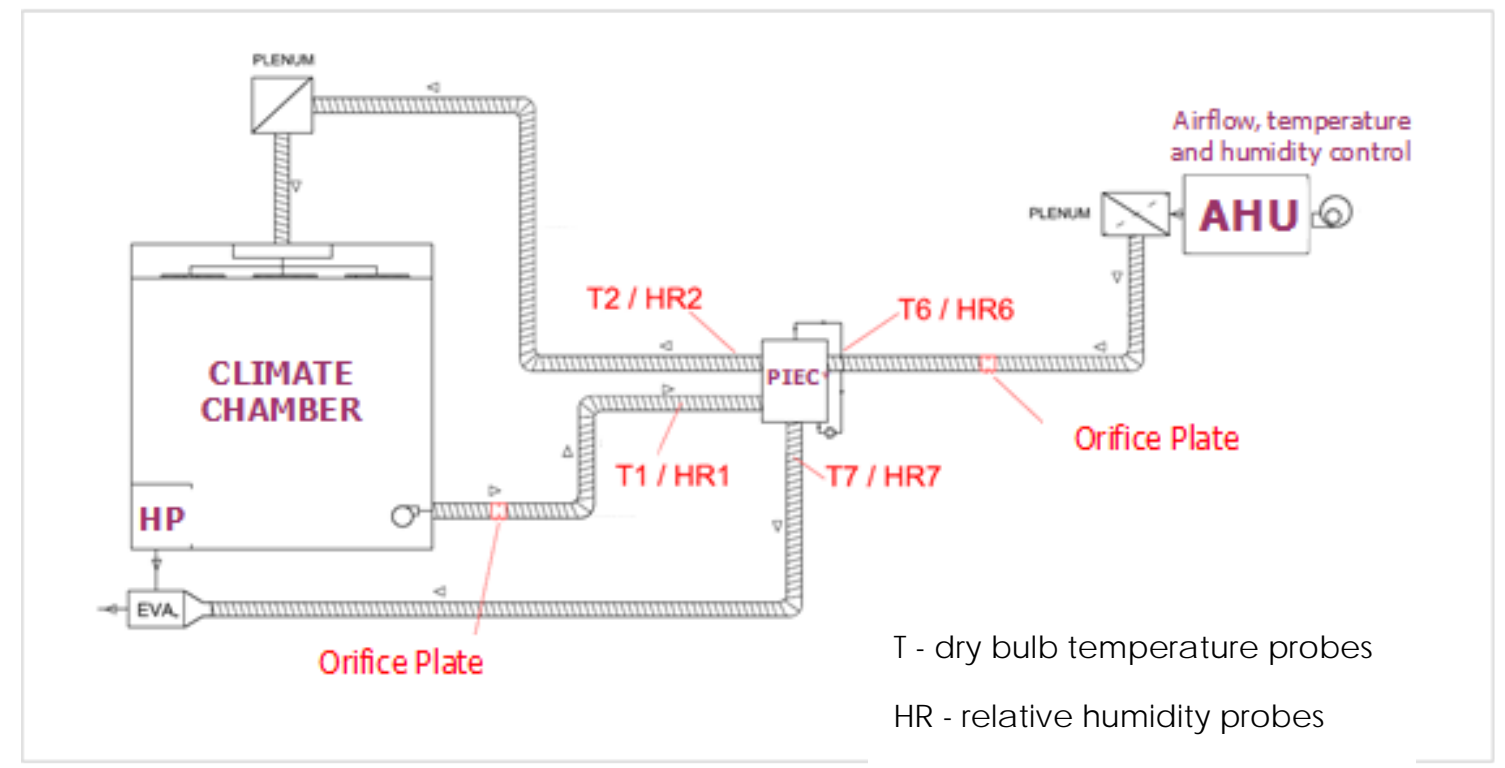

Fig. 4. Sc heme of the experimentall setup.

A second operating mode is performed by supplying water inside one of the system sides from an upper water distributor. This distributor consists on a shower that provides water that is afterwards uniformly supplied to the upper inlet of the hollow panels with the aid of a wire net. Then, water flows downwards inside the panels in direct contact and counter-flow with 
the exhaust airstream. Consequently, the systems operate as indirect evaporative coolers, ideally following an adiabatic process. This mode is developed to study how recovery of the exhaust air energy potential improves in each case by enabling evaporative cooling. Combining heat recovery and evaporative cooling could also be implanted by spraying water to the exhaust airstream before passing through the heat exchanger, as proposed in the Spanish nom [23]. However, the first altemative is preferred in this case because of its compactness.

\subsection{Design of experiments}

To experimentally determine both prototypes behaviour in both operating modes introduced, outdoor a irstream volume flow and dry bulb temperature have been varied and controlled. For each system working in each operating mode, a ir volume flow is varied from 125 to 400 $\mathrm{m}^{3} / \mathrm{h}$ whereas its dry bulb temperature is varied from 25 to $40^{\circ} \mathrm{C}$, as shown in table 2 . Thus, a total of 64 tests have been performed (32 tests for each system). Entering outdoor a ir humidity has not been considered a relevant factor for the experimental study because indirect evaporative cooling would be implemented in the retum airstream [14].

During the second operation mode (M2), water mass flow supplied has been maintained constant at approximately $0.11 \mathrm{~kg} / \mathrm{s}$ for all tests. Water temperature varies between 18 and $19.5^{\circ} \mathrm{C}$, depending on the partic ular test, which equals that of wet bulb of exhaust air at the system's outlet, as water supplied is recirc ulated; though it is influenced by the themal gains due to the waterpump and the heat exchanged with the outdoor airstream.

In every case exhaust air from the conditioned space is supplied to the system at a rate of $260 \mathrm{~m}^{3} / \mathrm{h}$ and is in comfort conditions. Thus, dry bulb temperature of exhaust air at the system's inlet is $22^{\circ} \mathrm{C}$ ( $\pm 0.5 \circ \mathrm{C}$ due to the sensitivity of the heat pump themostat), and relative humidity variation is restricted between 50 and $65 \%$; consequently the exhaust air wet bulb temperature varies between 14.5 and $17.5 \circ \mathrm{C}$, considering psychometric conditions at $698 \mathrm{~m}$ above sea level (tests developed in Valladolid, Spain).

Once operating in steady state, outdoor and exhaust airstreams dry bulb temperature and relative humidity at the system inlet and outlet are registered by the probes and measurement equipment.

To study how the different polycarbonate heat exchangers behaviour is influenced not only by outdoor airstream conditions, but also by evaporative cooling implementation, three parameters have been determined and compared: cooling capacity, themal effectiveness, and the global heat transfer coefficient. Finally, these parameters are compared for the two different structures designed, to analyse how performance could be improved by acting in the initial system design.

\section{Calculation}

Parameters considered for the analysis are defined following. 
For the basic operating mode (M1), dry bulb themal effectiveness is studied. When operating with outdoor airflows of 125 and $200 \mathrm{~m}^{3} / \mathrm{h}$, heat capacity rate of this cooled a ir would be determinant and thus the effectiveness should be expressed through equation (1) [24]:

$$
\varepsilon_{\mathrm{T}}=\frac{\mathrm{T}_{\mathrm{o} 1}-\mathrm{T}_{\mathrm{o} 2}}{\mathrm{~T}_{\mathrm{o}_{1}}-\mathrm{T}_{\mathrm{e} 1}}
$$

For the two remaining cases in which retum airflow is lower $\left(260 \mathrm{~m}^{3} / \mathrm{h}\right)$, dry bulb themal effectiveness is then calc ula ted as:

$$
\varepsilon_{\mathrm{T}}=\frac{\mathrm{T}_{\mathrm{e} 1}-\mathrm{T}_{\mathrm{e} 2}}{\mathrm{~T}_{\mathrm{o}_{1}}-\mathrm{T}_{\mathrm{e} 1}}
$$

Táble 1. Geometric c haracteristics

\begin{tabular}{ccc}
\hline Charac teristic & Type W & Type N \\
\hline Wall thic kness & $0.1 \mathrm{~mm}$ & $0.1 \mathrm{~mm}$ \\
\hline Panel thic kness “t” & $9 \mathrm{~mm}$ & $4 \mathrm{~mm}$ \\
\hline Height "H” & $0.62 \mathrm{~m}$ & $0.62 \mathrm{~m}$ \\
\hline Width "d" & $0.18 \mathrm{~m}$ & $0.18 \mathrm{~m}$ \\
\hline Length “L" & $0.23 \mathrm{~m}$ & $0.23 \mathrm{~m}$ \\
\hline Number of plates & 15 & 28 \\
\hline Geometry & Flat plates & Flat plates \\
\hline Heat exchange area & $3 \mathrm{~m}^{2}$ & $5.6 \mathrm{~m}^{2}$ \\
\hline
\end{tabular}

However, for the second operating mode (M2) in which the system works as an indirect evaporative cooler, studying the wet bulb themal effectiveness is preferable [8], and as the heat capacity rate of retum a ir is a lways deteminant in this case due to the energy involved in the water evaporation, it can be expressed as [24]:

$$
\varepsilon_{\mathrm{WBT}}=\frac{\mathrm{T}_{01}-\mathrm{T}_{02}}{\mathrm{~T}_{\mathrm{o}_{1}}-\mathrm{T}_{\mathrm{WB} 1}}
$$

To determine the amount of energy involved in the process, and thus quantify the cooling achieved in the outdoor airstream used for ventilation, cooling capacity is defined:

$$
\mathrm{E}_{\mathrm{CC}}=\dot{\mathrm{m}} \cdot\left(\mathrm{h}_{\mathrm{o} 1}-\mathrm{h}_{\mathrm{o} 2}\right)
$$

This parameter can be calculated as follows, because only sensible heat is involved:

$$
\mathrm{E}_{\mathrm{CC}}=\dot{\mathrm{m}} \cdot \mathrm{Cp}_{\mathrm{a}} \cdot\left(\mathrm{T}_{\mathrm{o} 1}-\mathrm{T}_{\mathrm{o} 2}\right)
$$

The heat exchangers global heat transfer coeffic ient is detemined through:

$$
\mathrm{U}=\frac{\mathrm{E}_{\mathrm{CC}}}{\mathrm{A} \cdot \Delta \mathrm{T}_{\mathrm{LM}}}
$$

Where:

$$
\Delta \mathrm{T}_{\mathrm{LM}}=\frac{\left(\mathrm{T}_{\mathrm{o} 1}-\mathrm{T}_{\mathrm{e} 2}\right)-\left(\mathrm{T}_{\mathrm{o} 2}-\mathrm{T}_{\mathrm{e} 1}\right)}{\ln \left(\frac{\left.\mathrm{T}_{01}-\mathrm{T}_{\mathrm{e} 2}\right)}{\left(\mathrm{T}_{\mathrm{o} 2}-\mathrm{T}_{\mathrm{e} 1}\right)}\right)}
$$

Instead of directly studying this last parameter, themal conductance will be defined as the product of the global heat transfer coefficient and the total heat exchange area, considered for the partic ular configuration of the heat-exchanger, to take these constructive charac teristic sinto consideration: 


$$
\mathrm{U} \cdot \mathrm{A} \cdot \mathrm{f}=\frac{\mathrm{E}_{\mathrm{CC}}}{\Delta \mathrm{T}_{\mathrm{LM}}}
$$

Table 2. Design of Experiments

\begin{tabular}{|c|c|c|c|}
\hline Systems studied & Operation modes & $\begin{array}{l}\text { Outdoor Air Volume Fow V } \\
\qquad\left[\mathrm{m}^{3} / \mathrm{h}\right]\end{array}$ & $\begin{array}{c}\text { Outdoor air Dry Bulb } \\
\text { Temperature T[o्C] }\end{array}$ \\
\hline \multirow[t]{2}{*}{ NP } & \multirow[t]{2}{*}{ M1- Dry (basic) } & V1- 125 & T1- 25 \\
\hline & & V2- 200 & $\mathrm{~T} 2-30$ \\
\hline \multirow[t]{2}{*}{ WP } & \multirow{2}{*}{$\begin{array}{c}\text { M2- Indirect } \\
\text { evaporative cooling }\end{array}$} & V3- 300 & T3- 35 \\
\hline & & V4- 400 & T4- 40 \\
\hline
\end{tabular}

For low outdoor air temperatures, the scarce difference between this variable and the exha ust a ir dry bulb temperature, which is in comfort conditions, genera tes instabilities in the thermal effectiveness expression, eq. (1), and the logarithmic mean temperature difference, eq. (7), because the difference between these two temperatures in the denominator tends to 0 . Thus, the parameters: dry bulb themal effectiveness and themal conductance are not representative for an outdoor a ir temperature at the inlet of $25^{\circ} \mathrm{C}$, and will not be studied in these conditions.

\section{Results and Disc ussion}

\subsection{Thermal effectiveness}

Dry bulb thermal effec tiveness is studied for both systems in the first operating mode, whereas wet bulb themal effectiveness is observed when operating as ind irect evaporative coolers. Table 3 gathers results obtained in these cases.

For both systems, themal effectiveness does not vary signific antly with outdoor a ir entering temperature. The same happens with the wet bulb thermal effectiveness. This is because the temperature drop clearly increases for higher values of outdoor air dry bulb temperature at the inlet, due to the increased heat transfer obtained as a consequence of the also higher temperature difference between both airstreams; but as the maximum temperature drop achievable also increases with the outdoor a ir temperature, this last factor does not have effect on these two parameters. On the other hand, an increase in the outdoor air volume flow improves heat transfer, as will be seen in subsection 4.3. Consequently, for cases where outdoor air heat capacity is deteminant, higher a ifflows provide better results. This can be observed comparing themal effectiveness between 400 and $300 \mathrm{~m} / \mathrm{h}$ in $\mathrm{Ml}$. For the remaining cases in which exhaust air flow heat capacity is the deteminant one, however, higher aifflows incur in lower effectiveness, due to the expression of the parameter (see eq. (1)).

Studying both systems as simple heat exchangers, it can be seen that values obtained in M1 range from 0.28 to 0.46 and from 0.33 to 0.42 for the NP and WP, respectively. These results fall below the ones that could be expected in a theoretic al unmixed cross-flow heat exchanger, which could reach from 0.4 up to 0.59 and 0.48 for each device.

Results for the NP in terms of dry bulb themal effectiveness a re signific antly better than those for the WP, whereas this difference is not so outstanding when comparing both prototypes in 
$M 2$, in terms of wet bulb themal effectiveness. This implies a negligible effect of modifying the heat exchange area maintaining the overall size when operating as indirect evaporative coolers, which could be due to the more appropriate constructive characteristics of the WP (hollow panels' width) in terms of a ir-water distribution in the retum air side of the heatexchanger.

These trends observed did not seem to apply so clearly to the lowest exhaust a ir volume flow, because operating conditions in some tests where not stable. It was checked that tests performed in these conditions showed deviations in the values registered for the exhaust air volume flow, which is successfully maintained close to $260 \mathrm{~m}^{3} / \mathrm{h}$ for the remaining tests. Unfortunately, for ventilation rates of $125 \mathrm{~m}^{3} / \mathrm{h}$ this variability resulted to be unavoidable in most cases, due to the higher exhaust a ir volume flow and consequent depression in the climate chamber. This generates uncontrolled conditions which affect operation of the whole installation, as for example during some tests when the relative humidity in the laboratory was afterwards checked to have been particularly high. Consequently, results for the lowest a irflow tested would not be especially representa tive and thus are not provided.

Table 3. Themmal and wet bullb themal effec tiveness.

\begin{tabular}{|c|c|c|c|c|c|}
\hline \multirow{3}{*}{$\begin{array}{c}V \\
{\left[\mathrm{~m}^{3} / \mathrm{h}\right]}\end{array}$} & \multirow{3}{*}{$\begin{array}{l}\text { To1 } \\
\text { [C] }\end{array}$} & \multicolumn{2}{|c|}{ M1 } & \multicolumn{2}{|c|}{ M2 } \\
\hline & & NP & WP & NP & WP \\
\hline & & $\varepsilon_{T}[\% / 1]$ & $\varepsilon_{T}[\% / 1]$ & $\varepsilon_{\text {WBT }}[\% 1]$ & $\varepsilon_{\text {WBT }}[\% 1]$ \\
\hline \multirow{4}{*}{400} & 40 & 0.42 & 0.36 & 0.29 & 0.31 \\
\hline & 35 & 0.46 & 0.34 & 0.27 & 0.32 \\
\hline & 30 & 0.39 & 0.33 & 0.23 & 0.34 \\
\hline & 25 & - & - & 0.23 & 0.43 \\
\hline \multirow{4}{*}{300} & 40 & 0.40 & 0.33 & 0.35 & 0.28 \\
\hline & 35 & 0.33 & 0.35 & 0.30 & 0.28 \\
\hline & 30 & 0.28 & 0.42 & 0.30 & 0.29 \\
\hline & 25 & - & - & 0.27 & 0.27 \\
\hline \multirow{4}{*}{200} & 40 & 0.46 & 0.37 & 0.40 & 0.33 \\
\hline & 35 & 0.44 & 0.37 & 0.39 & 0.36 \\
\hline & 30 & 0.43 & 0.38 & 0.37 & 0.34 \\
\hline & 25 & - & - & 0.35 & 0.31 \\
\hline
\end{tabular}

\subsection{Cooling capacity}

Contrary to the temperature drop and the themal effectiveness, the cooling capacity is related to the air mass flow treated by the system. Consequently, it appears as a more interesting parameter in terms of performance, as energy involved is considered.

As can be seen in figures $5 a$ and $5 b$, for the WP, it shows an increasing trend with the variation of the outdoor a ir temperature, and improves with higher volume flows, due to the improvement introduced in the heat transfer convective coefficients. The same behaviour was observed from the characterization of the NP [8]. 


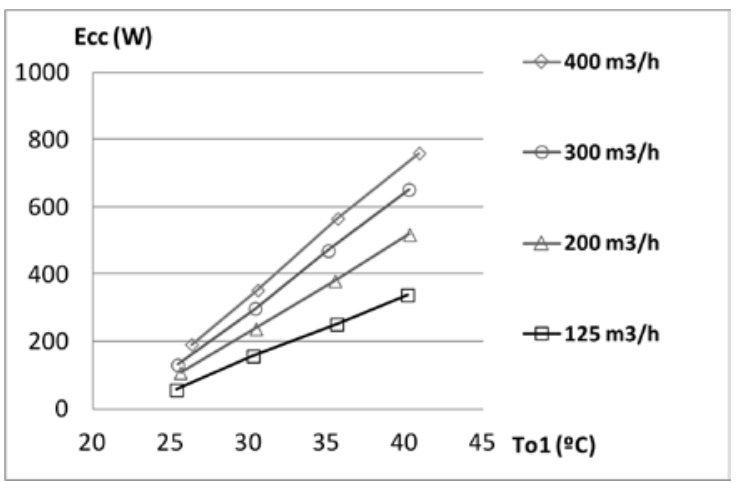

Fig. 5. a. Cooling capacity for WP, M1

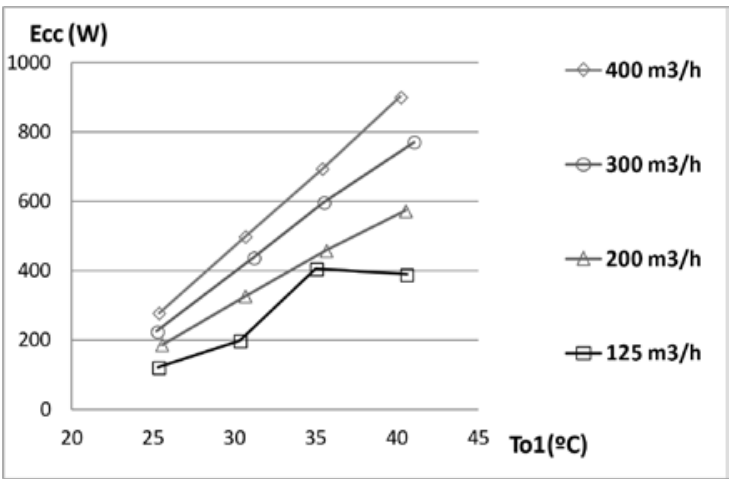

Fig. 5. b. Cooling capacity for WP, M2

Evaporative cooling implementation permits achieving higher cooling capacities in both systems. However, comparing results obtained for both prototypes, performance scarcely improves for NP system, in which the heat exchange area is twofold. Table 4 gathers the linear regressions obta ined for the tests in M2. It was also seen in this case that results for the lowest a ir volume flows were less representative, especially for the WP.

Ta ble 4. Linear regressions for systems operating as indirect eva porative coolers.

\begin{tabular}{|c|c|c|c|c|}
\hline \multirow[t]{2}{*}{$V\left[m^{3} / h\right]$} & \multicolumn{2}{|l|}{ NP - M2 } & \multicolumn{2}{|l|}{ WP- M2 } \\
\hline & Linear reg ression & $\mathrm{R}^{2}$ & Linear regression & $\mathrm{R}^{2}$ \\
\hline 125 & $\mathrm{EC} C=385.80+20.973 \cdot \mathrm{T}_{01}$ & 0.9978 & Ec $c=370.48+19.754 \cdot \mathrm{T}_{01}$ & 0.8335 \\
\hline 200 & $E c c=584.36+30.45 \cdot \mathrm{T}_{01}$ & 0.999 & $\mathrm{Ecc}=467.76+25.82 \cdot \mathrm{T}_{01}$ & 0.9989 \\
\hline 300 & $\mathrm{Ecc}=789.59+39.99 \cdot \mathrm{T}_{01}$ & 0.9989 & $\mathrm{Ecc}=651.88+34.87 \cdot \mathrm{T}_{01}$ & 0.9988 \\
\hline 400 & $E c c=817.36+42.00 \cdot T_{01}$ & 0.9866 & $\mathrm{Ecc}=782.96+41.82 \cdot \mathrm{T}_{\mathrm{o}}$ & 1 \\
\hline
\end{tabular}

\subsection{Themal conductance}

The parameter defined as themal conductance for the particular configuration (table 5) remains fairly constant with the outdoor a ir entering temperature. These results appear predictable, considering that the global heat transfer coeffic ient is related to the achieved cooling capacity, but neutralises the temperature drop value by introducing the logarithmic mean temperature differences. On the other hand, values for the themal conductance improve when higher airflows are tested, which could be due to convective coefficients improvement in the heat exchanger outdoor a ir side as a consequence of being operating with such higher a irflows.

Táble 5. Thermal conductance

\begin{tabular}{|c|c|c|c|c|c|}
\hline \multirow{4}{*}{$\begin{array}{c}V \\
{\left[\mathrm{~m}^{3} / \mathrm{h}\right]}\end{array}$} & \multirow{4}{*}{$\begin{array}{l}T_{01} \\
{[C]}\end{array}$} & \multicolumn{2}{|c|}{ M1 } & \multicolumn{2}{|c|}{ M2 } \\
\hline & & NP & WP & NP & WP \\
\hline & & UA·f & UA·f & UA'f & UA·f \\
\hline & & {$\left[\mathrm{W} /{ }^{\circ} \mathrm{C}\right]$} & {$\left[\mathrm{W} /{ }^{\circ} \mathrm{C}\right]$} & {$\left[\mathrm{W} /{ }^{\circ} \mathrm{C}\right]$} & {$[\mathrm{W} / \stackrel{\mathrm{O}}{\mathrm{C}}]$} \\
\hline \multirow{3}{*}{400} & 40 & 263.4 & 181.4 & 258.0 & 194.3 \\
\hline & 35 & 275.5 & 176.5 & 246.8 & 195.4 \\
\hline & 30 & 258.8 & 190.7 & 238.7 & 207.9 \\
\hline \multirow{2}{*}{300} & 40 & 235.6 & 166.1 & 224.1 & 162.3 \\
\hline & 35 & 189.4 & 158.0 & 206.6 & 170.2 \\
\hline
\end{tabular}




\begin{tabular}{c|ccccc}
\hline & 30 & 164.1 & 168.4 & 229.7 & 182.5 \\
\hline \multirow{2}{*}{$\mathbf{2 0 0}$} & $\mathbf{4 0}$ & 198.4 & 136.8 & 185.3 & 134.9 \\
& $\mathbf{3 5}$ & 190.2 & 136.8 & 183.4 & 141.3 \\
& $\mathbf{3 0}$ & 188.8 & 142.1 & 192.2 & 150.2 \\
& $\mathbf{4 0}$ & 74.2 & 89.2 & 135.8 & 92.5 \\
& $\mathbf{3 5}$ & 85.3 & 95.9 & 137.0 & 113.4 \\
\hline
\end{tabular}

The main comparison among systems performance must be raised in tems of heat tranfer, where the two constructive differences have key roles. Actually, themal conductance obtained in M1 is better for the NP, whereas in M2 improvement introduced by doubling the heat exchange area is not as good. Results also show that heat transfer is being improved in M2 for WP in a way that does not have effect on the NP. Considering that the themal conductance for NP in M2 does not improve in the same proportion as it does for WP, it can be inferred that the narrow geometry of the polycarbonate panels in this case hinders the water distribution. A possible explanation could be that in the NP some paths inside the hollow panels might be filled with water while others would be completely dry. As in that case part of the device would be operating as a water-to-air heat exchanger and other part as it did in $M 1$, its performance would worsen in comparison to the case where the entire device would be operating in an indirect evaporative cooling mode. This is because air evaporatively cooled in the retum side would ideally reach the adiabatic saturation temperature, which coincides with that of recirculated water, and thus in the NP temperature differences between both sides all throughout the heat exchanger would not be the maximum achievable in $\mathrm{M} 2$.

Consequently, wider panels in the WP could be favouring a ir-water flow through them and thus the air evaporative cooling, improving the heat transfer process. The merely slightly better results observed in some parameters when doubling the heat exchange area (facing NP to WP) would be due to the effect of this characteristic being compensated by the improvement introduced by widercross sections.

\subsection{Analysis of Vaniance}

Finally, to study the relative influence that each constructive issue has on results obtained, an Analysis of Variance is developed for every parameter calculated. Table 6 gathers the various factors percentage contributions.

Table 6. Percenta ge contributions of the factors varied in the tests a nd their interac tion, obtained

through an Analysis of Variance.

\begin{tabular}{cccccccccccc}
\hline & $\begin{array}{c}\text { SSP } \\
{[\%]}\end{array}$ & $\begin{array}{c}\text { SSM } \\
{[\%]}\end{array}$ & $\begin{array}{c}\text { SSV } \\
{[\%]}\end{array}$ & $\begin{array}{c}\text { SST } \\
{[\%]}\end{array}$ & $\begin{array}{c}\text { SSPM } \\
{[\%]}\end{array}$ & $\begin{array}{c}\text { SSPV } \\
{[\%]}\end{array}$ & $\begin{array}{c}\text { SSPT } \\
{[\%]}\end{array}$ & $\begin{array}{c}\text { SSMV } \\
{[\%]}\end{array}$ & $\begin{array}{c}\text { SSMT } \\
{[\%]}\end{array}$ & $\begin{array}{c}\text { SSVT } \\
{[\%]}\end{array}$ & $\begin{array}{c}\text { SSREmor } \\
{[\%]}\end{array}$ \\
\hline$\varepsilon T$ & 3.21 & - & 44.01 & 0.24 & - & 14.41 & 10.17 & - & - & 14.10 & 13.86 \\
$\varepsilon$ [\%H & 1.13 & - & 38.22 & 6.36 & - & 28.49 & 3.79 & - & - & 9.91 & 12.10 \\
ECC & 0.03 & 7.37 & 13.13 & 52.63 & 0.25 & 1.36 & 1.40 & 1.07 & 1.40 & 6.82 & 14.54 \\
U.A & 9.91 & 6.01 & 46.49 & 18.93 & 0.04 & 0.65 & 0.33 & 0.62 & 5.93 & 1.12 & 9.97 \\
\hline
\end{tabular}


Results highlight the important role that factor outdoor air dry bulb temperature has on parameter cooling capacity. It is a Iso proved the effect of a ir volume flow expected. This last factor has great weight on the themal conductance, as it clearly detemines the convective coeffic ients in the heat transfer process; as well as on the themal effectiveness.

Finally, effects of factors "prototype" and "mode" do not appear to be so outstanding. This could prove the explanation proposed conceming the possible compensation of favourable effects introduced by increased heat exchange area and wider flow-paths through the polycarbonate panels. Larger heat exchange implemented in the design of the NP implies na rrower flow-paths, and the opposite happens in the WP. Moreover, it has been deducted that larger areas improve systems performance when operating as simple heat exchangers, and that wider paths favour air-water distribution as indirect evaporative coolers. Consequently, their effect on each prototype and mode results would compensate, which is now corroborated in the ANOVA.

\section{Ventilation cooling loads covered and energy savings}

It can be observed from the experimental study developed on the prototypes behaviour that such simple and small devices can be interesting for pre-cooling ventilation air taking advantage of retum a ir residual energy, especially when operating as ind irect evaporative coolers; and thus reduce energy consumed by conventional systems to reach comfort conditions indoors. In this section, experimental results obta ined a re used to estimate success in covering ventilation cooling loads, and predict energy savings introduced with these devices.

In table 4 linear regressions for the cooling capacity were gathered, which appears to be the most interesting parameter when aiming to study the prototypes actual cooling potential. The second operating mode is the one considered, due to the better results observed in these cases. Only results for the three highest levels of outdoor a irflow a re considered, because the lowest a ifflow would not fit to the minimum real ventilation a irstreams required in most cases, and furthermore might not be representative due to experimental variability already indicated.

As ventilation cooling demand would vary among different c limates, four cases a re studied, corresponding to different Spanish cities classified in the four categories distinguished in the Spanish nom according to climate harshness during summer [25], from milder to harsher climate: Bilbao, Valladolid, Madrid and Seville. Ventilation cooling load during summer season (from $1^{\text {st }}$ of May to $30^{\text {th }}$ September) is calculated from meteorological data through equation:

$$
\mathrm{Q}=\frac{\mathrm{v}}{\mathrm{v}_{\mathrm{e}}} \cdot \mathrm{c}_{\mathrm{p}} \cdot\left(\mathrm{T}_{\mathrm{o} 1}-22^{\mathrm{o}} \mathrm{C}\right)
$$

Where $C_{p}$ is the air specific heat capacity $\left(1012 \mathrm{~J} /\left(\mathrm{kg}^{\circ} \mathrm{C}\right)\right)$ ), and the specific volume $v_{e}$ would be calculated depending on the city altitude (a). Load is calculated considening an indoor set temperature of $22^{\circ} \mathrm{C}$, for being this one the themal comfort temperature set inside the climate chamber during the tests. Then, for the whole cooling period, the total ventilation 
cooling demand will be the sum of the loads during the hours when $T_{01}>22^{\circ} \mathrm{C}$. This will be the number of hours during which the devices will be operating $(n)$. Values for a required ventilation airstream of 200,300 and $400 \mathrm{~m}^{3} / \mathrm{h}$ in the four cities considered are given in table 7.

Considering that the prototypes will be capable of supporting ventilation a irstream cooling loads corresponding to their cooling capacity, there will be periods of time duning which the systems will be able to cover the whole ventilation cooling load and even supply extra cooling capacity; and the remaining period they will only be capable of covering a certain percentage of this load. Percentages of covered ventilation load in each case have been calculated on this base, and are shown in table 7.

Table 7. Percentage of ventilation demand supported and percentage of energy saved expected.

\begin{tabular}{|c|c|c|c|c|c|c|}
\hline \multirow[b]{2}{*}{ Location } & \multirow[b]{2}{*}{$\begin{array}{c}V \\
{\left[\mathrm{~m}^{3} / \mathrm{h}\right]}\end{array}$} & \multirow[b]{2}{*}{$\begin{array}{l}\text { EvcD } \\
\text { [kWh] }\end{array}$} & \multicolumn{2}{|c|}{ NP - M2 } & \multicolumn{2}{|c|}{ WP - M2 } \\
\hline & & & $\begin{array}{l}\text { Evcc } \\
{[\%]}\end{array}$ & $\begin{array}{l}\text { Es } \\
{[\%]}\end{array}$ & $\begin{array}{l}\text { Evcc } \\
{[\%]}\end{array}$ & $\begin{array}{c}\text { Es } \\
\text { [\%] }\end{array}$ \\
\hline BILAAO & 200 & 130.02 & $80.35 \%$ & $51.51 \%$ & $79.48 \%$ & $50.48 \%$ \\
\hline$a=6 m$ & 300 & 195.03 & $67.27 \%$ & $48.14 \%$ & $68.88 \%$ & $49.67 \%$ \\
\hline$n=744$ hours & 400 & 260.04 & $57.47 \%$ & $42.93 \%$ & $58.43 \%$ & $44.08 \%$ \\
\hline VAШADOUD & 200 & 303.54 & $75.21 \%$ & $57.36 \%$ & $71.90 \%$ & $54.05 \%$ \\
\hline$a=698 m$ & 300 & 455.32 & $61.98 \%$ & $50.04 \%$ & $62.41 \%$ & $50.42 \%$ \\
\hline$n=1082$ hours & 400 & 607.09 & $50.91 \%$ & $41.95 \%$ & $54.71 \%$ & $45.74 \%$ \\
\hline MADRID & 200 & 391.37 & $74.52 \%$ & $56.23 \%$ & $71.63 \%$ & $53.17 \%$ \\
\hline$a=655 m$ & 300 & 587.06 & $61.21 \%$ & $48.95 \%$ & $61.84 \%$ & $49.60 \%$ \\
\hline$n=1430$ hours & 400 & 782.74 & $50.90 \%$ & $41.68 \%$ & $53.94 \%$ & $44.74 \%$ \\
\hline SEVIUA & 200 & 880.47 & $64.87 \%$ & $52.53 \%$ & $60.68 \%$ & $48.38 \%$ \\
\hline$a=11 m$ & 300 & 132.70 & $54.22 \%$ & $46.04 \%$ & $52.50 \%$ & $44.30 \%$ \\
\hline$n=2172$ hours & 400 & 1760.94 & $44.33 \%$ & $38.18 \%$ & $46.40 \%$ & $40.26 \%$ \\
\hline
\end{tabular}

The percentage of energy savings that could be achieved can be calculated as:

$$
\mathrm{E}_{\mathrm{S}}[\%]=\frac{\mathrm{E}_{\mathrm{S}}}{\left(\mathrm{E}_{\mathrm{VCD} / \mathrm{COP}}\right)}
$$

Where the energy saved will be the difference between the required electric energy consumed by a heat pump to support the ventilation cooling demand that could be covered by the altemative systems, and the electric energy consumed by them during their operation period:

$$
\mathrm{E}_{\mathrm{S}}[\mathrm{kWh}]=\frac{\mathrm{E}_{\mathrm{VCC}}}{\mathrm{COP}}-\mathrm{n} \cdot \mathrm{P}
$$

For the analysis, a Coeffic ient of Performance COP of 2.5 is considered for the conventional heat pump air-conditioning system; whereas an electric power consumption of $20 \mathrm{~W}$ would be required for the prototypes operation, corresponding to the water pump needed. Increase in fans power due to additional pressure drop introduced is assumed to be negligible due to the insignificant contraction and expansion of the airflow in the heat exchanger, and the short air paths of the prototypes. Measured pressure drops already validated this hypothesis. 
Results gathered in table 7 show how such small and simple devices can be expected to cover from $45 \%$ to $80 \%$ of the ventilation cooling demand during summer period, depending on the ventilation airflow requirements and climate harshness. Furthemore, this leads to energy savings of a round $50 \%$.

Additional fan power required might nevertheless reduce these energy savings. The extra pressure drop depends on the air path length and the equivalent diameter, and on the friction factor, which is linearly dependant to the square root of Reynolds number for laminar flows. Consequently, small pressure drops measured and calculated for a plate heat exchanger according to Kays\&London [26] validate these results in the case of the WP, where it never exceeds 1.2 $\mathrm{Pa}$ in the outdoor air side and is below $17 \mathrm{~Pa}$ in the exhaust air side, and thus no signific ant extra power consumption would be needed. On the other hand, pressure drop in the outdoor air side of the NP scarcely reaches $4 \mathrm{~Pa}$, though in the exhaust a ir side increases up to $60 \mathrm{~Pa}$ due to the longer and narrower a ir paths. Nonetheless, pressure drop of $60 \mathrm{~Pa}$ when operating with an exhaust a ir flow of $260 \mathrm{~m}^{3} / \mathrm{h}$ would still involve low extra fan power, in comparison to the already existing pressure drops in the whole air ventilation system.

\section{Conclusions}

In this work, the recovering of a n exha ust a irstream from a conditioned space residual energy has been performed through small and simple polycarbonate heat exchangers of same size but different constructive characteristics: total heat exchange area and airstreams paths. They have been tested as ind irect eva porative coolers to study how this effect could improve heat-recovery. It has been seen that implementing evaporative cooling in the heat recovery process leads to an increase in the cooling capacities of about a $13 \%$.

These simple devices could achieve energy savings of a round $50 \%$ by covering from $45 \%$ to $80 \%$ of the ventilation cooling demand during summer period, depending on the climate, for required outdoor a irflows corresponding to the ones tested: 200,300 and $400 \mathrm{~m} 3 / \mathrm{h}$.

Both prototypes operate better for higher outdoor a ir temperatures in whatever operating mode, which improves their behaviour in harsher climates, despite the greater difficulty of supporting expected ventilation cooling loads.

cooling capacity is always better when operating with higher a ir volume flows. The a nalysis of this parameter appears to be the most interesting one in terms of performance, because thermal effectiveness merely provides a reference to the maximum heat exchange affordable, which actually depends on global heat exchange coeffic ient and mass flow.

In an indirect evaporative cooling mode, themal conductance does not vary significantly when modifying the system total heat exchange area maintaining the overall size, due to compensation with the better a ir-water distribution inside wider hollow panels. Consequently, it can be deducted that polycarbonate panels' width must be a determining characteristic in the systems performance when combining heat recovery and evaporative cooling together in a unique device. 
Taking all this into account, the new prototype constructed with wider panels would provide results as interesting as the ones obta ined from the original NP, of larger heat exchange area, with less material necessity for its construction. A twofold-area device constructed with wide panels would be much more sizeable and thus disregarded, as its compactness and cheapness particularly make these systems still more interesting than the separated-systems altemative proposed by the Spanish nom.

\section{Nomenclature}

t: Panel thic kness ( $\mathrm{mm}$ )

$\mathrm{H}$ : Prototype height $(\mathrm{m})$

$\mathrm{d}$ : Prototype width $(\mathrm{m})$

L: Prototype length $(\mathrm{m})$

V: Air volume flow $(\mathrm{m} 3 / \mathrm{h})$

T: Temperature (으)

$\Delta \mathrm{T}$ : Temperature drop (으)

$\varepsilon$ T. Dry bulb themal effectiveness

$\varepsilon$ WBT: Wet bulb themal effectiveness

Ecc: Cooling capacity (W)

h: Specific enthalpy (kJ/kgda)

U: G lobal Heat Transfer Coeffic ient (W/K.m2)

\section{A: Area $(\mathrm{m} 2)$}

UA: Themal conductance (W/K)

m: Dry Air mass flow (kgda/s)

$\triangle$ TLM: Log mean temperature difference $(K)$

f: Correction factor on the $\triangle T L M$ for non-countercurrent heat-exchanger

SS: Percentage contribution of factori (\%)

SSij: Percentage contribution of interaction between factors i and $\mathrm{j}$ (\%)

SSREmor: Perc entage contribution of remaining uncontrolled factors and interactions (\%)

Q: Ventilation cooling load (kW)

$v_{e}$ : Specific volume $(\mathrm{m} 3 / \mathrm{kg})$

$\mathrm{C}_{\mathrm{p}}$ : Spec ific heat capacity of a ir $\left(1012 \mathrm{~J} /\left(\mathrm{kg}^{\circ} \mathrm{C}\right)\right)$

a: Altitude above sea level $(\mathrm{m})$

EvcD: Total ventilation cooling demand (kWh) 
Evcc: Ventilation cooling demand covered [\%]

Es: Energy savings [kWh]

$\mathrm{N}$ : Number of operating hours (h)

P: Electric powerconsumed by the prototypes (W)

\section{Abbreviations}

NP: Na row-panels prototype

WP: Wide-panels prototype

M1: Basic operating mode

M2: Indirect evaporative cooling operating mode

PIEC: Polycarbonate Indirect Eva porative Cooler

HP: Heat Pump

AHU: Air Handling Unit

\section{Subindexes}

01: Outdoor a ir at system's inlet

02: Outd oor a ir at system's outlet

e1: Exha ust a ir at system's inlet

e2: Exhaust a ir at system's outlet

wb: Wet Bulb temperature

t: Dry bulb temperature

da: Dry air

NP: Na row panels prototype

WP: Wide panels prototype

P: Factor "prototype"

M: Factor "operating mode"

T: Factor "outdoorair dry bulb temperature"

V: Factor "outdoor air volume flow"

\section{Acknowledgements}

This work forms part of the research being carred out within the framework of the "Reduction of energy consumption and carbon dioxide emission in buildings combining evaporative cooling, free cooling and energy recovery in all-a ir systems", project supported by the Ministry of Science and Technology through the call for scientific research and technological development research projects. Reference numberENE2008-02274/CON. 
Manuel Andrés-Chicote wants to thank to the Spanish Govemment for the support given through the FPU (Formación de Profesorado Universitario). Reference: AP2010-2449.

\section{References}

[1] 2010, 'Energy 2020 - A strategy for competitive, sustainable and secure energy', Communication from the Commission to the European Parliament, the Council, the European Economic and Social Committee and the Committee of the Regions. URL: http://eur-lex.europa.eu/LexUriServ/LexUriServ.do? uni=CO M:2010:0639:FIN:EN:PDF(Date of last ac cess: 2 nd J uly 2012).

[2] Energy Performance of Buildings Directive, concerted action. URL: http://www.epbdca.org (Date of last access: 2nd J uly 2012).

[3] B.R. Hughes, H.N. Chaudhry, S.A. Ghani, A review of susta inable cooling technologies in buildings, Renew. Sust. Energ. Rev.; 15 (2011) 3112- 3120.

[4] A. Mardiana-Idayu, S.B. Riffat, Review on heat recovery technologies for building applic a tions, Renew. Sust. Energ. Rev.,, 16 (2012) 1241-1255.

[5] ASHRAE, ASHRAE Hand book 2000: Systems and Equipment. Cha pter 44. Air-to-a ir Energy Recovery, Atlanta (U.S.A), 2000.

[6] F.J. Rey Martínez, J.F. San José Alonso, E. Velasco Gómez, M.A. Álvarez-Guerra Plasencia, Heat recovery in a ir-conditioning systems, Technical doc uments for themal instalations in buildigns DTIE 8.01, El Instalador (ATECYR),Madrid (Spain), 2000. (In Spanish).

[7] L. Schibuola, High-effic iency recovery for a ir-conditioning applications in a mild climate: a case study, Appl. Them. Eng.,,17, No. 5 (1997)447-454.

[8] E. Velasco Gómez, A. Tejero González, F.J . Rey Martínez, Experimental characterization of an ind irect evaporative cooling prototype in two operating modes, Appl. Energy, 97 (2012) 340-346.

[9] F.J . Rey Martínez, M.A. Álvarez-Guerra Plasencia, E. Velasco Gómez, F. Varela Díez, R. Herrero Martín, Design and experimental study of a mixed energy recovery system, heat pipes and indirect eva pora tive equipment for a ir conditioning, Energy Build., 35 (2003) 1021-1030.

[10] J.R. Watt, Evaporative Air Conditioning Handbook, Chapman \& Hall, New York (U.S.A.), 1986.

[11] M.F. El-Refaie, S. Kaseb, Speculation in the feasibility of evaporative cooling, Build. Environ., 44 (2009) 826-838.

[12] F.J. Rey Martínez, E. Velasco Gómez, A. Tejero González, F.E. Flores Murieta, Comparative study between a ceramic evaporative cooler (CEC) and an a ir source heat pump applied to a dwelling in Spa in, Energy Build. 42 (2010) 1815-1822. 
[13] M. Steeman, A. Janssens, M. De Paepe, Performance evaluation of indirect evaporative cooling using whole-building hygrothemal simulations, Appl. Therm. Eng., 29 (2009) 2870-2875.

[14] G.P. Maheswari, F. Al-Ragom, R.K. Suri, Energy-saving potential of an indirect evaporative cooler, Appl. Energy, 69 (2001) 69-76.

[15] S. Jaber, S. Ajib, Energy Recovery system in Mediterranean region, Sustainable Cities and Society, 3 (2012) 24-29.

[16] ASHRAE, ASHRAE Handbook, 2000: Systems and Equipment. Chapter 19. Eva porative a ir cooling equipment, Atlanta (U.S.A), 2000.

[17] X. Zhao, L. Shuli, S.B. Riffat, Comparative study of heat and mass exchanging materials for ind irect eva pora tive cooling systems, Build. Environ., 43 (2008)1902-1911.

[18] D. Pescod, An evaporative a ir cooler using a plate heat exchanger, Tech. Rep. No. 2, Division of Mechanic al Engineering, CSIRO, Highett, Vic toria (Austra lia),1974.

[19] C.T. Joen, Y. Park, Q. Wang, A. Sommers, X. Han, A. Jacobi, A review on polymer heat exchangers for HVAC\&R a p plic ations, Int. J. Refrig.-Rev. Int. Froid, 32 (2009) 763 - 779.

[20] S. Delfani, J. Esma eelian, H. Pasdarshahrib, M. Karamia, Energy saving potential of an indirect eva porative cooler as a pre-cooling unit for mechanical cooling systems in Iran, Energy Build., 42 (2010)2169-2176.

[21] G. Heidaninejad, M. Bozorgmehr, S. Delfani, J. Esmaeelian, Experimental investigation of two-stage indirect/direct evaporative cooling system in various climatic conditions, Build. Environ., 44 (2009) 2073-2079.

[22] J. Kragh, J. Rose, T.R. Nielsen, S. Svendse, New counter Flow heat exchanger designed for ventilation systems in cold c limates, Energy Build., 39 (2007)1151-1158

[23] Spanish Ministry of Industry, Tourism and Market \& Spanish Ministry of Housing,..Spanish Nom: Royal Order 1027/2007: Spanish Regulation of Thermal Installations and Buildings, 2007. (In Spanish)

[24] S.K. Wang, Incomprating Evaporative Cooling with Other Coolers, Handbook of AirConditioning and Refrigeration, McGraw Hill, New York (U.S.A.) 1994.

[25] Spanish Ministry of Industry, Tourism and Market \& Spanish Ministry of Housing, Spanish Norm: Royal Order 315/2006 of 17th March: Spanish Technical Building Code. Part 1. 2006. (In Spanish).

[26] W.M. Kays, A.L. London, Compact heat exchangers, McGraw-Hill, New York (U.S.A.), 1984. 